\title{
The Inclusion of a Student Voice in Teacher Professional Learning to Create Relevance in Science Education
}

\author{
Anders Jidesjö \\ Department of Environmental Change, Linköping University, SE-581 83 Linköping, Sweden. \\ Email: anders.jidesjo@liu.se
}

Received: 21 January 2021; Revised: 16 March 2021; Accepted: 25 March 2021

\begin{abstract}
Students' perceptions of a lack of relevance in science and technology (S\&T) education have been reported in research and policies for a long time. In many countries this is a problem that is not decreasing despite numerous measures to address it. In the study presented here a new approach to the problem was developed and empirically tested. The study targets the theoretical development of "teacher professional learning". Key elements of the approach include distributed leadership with adaptive expertise, boundary spanners to relate leadership structures to student learning, and facilitators to initiate such work. Five Swedish municipalities were involved in this approach, from a model where 10 core concepts were adapted to the Swedish educational context and incorporated in a professional learning model. The model suggests including two initial steps to create a professional learning cycle, e.g. students' and teachers' needs together with leadership structures. The empirical evidence comes from pre-studies investigating these two initial steps with a qualitative research design. The results are compiled in five themes showing that learners, teachers and school leaders perceive S\&T education to be 'special' and describe progression, organization and beneficial changes. Facilitators were found to be important and organizational relationships were described and discussed. Differences in the nature of the relevance problem between students and their teachers and in different parts of the educational system were also identified, which have consequences for the progression in a professional learning cycle. This is discussed and pointed out as important for future research. Overall, the results indicate that published notions regarding teacher professional learning and students' perceptions of S\&T education, can be combined to formulate a robust new approach to address the relevance problem.
\end{abstract}

Keywords: teacher's professional learning, student's voice, science education

\section{Introduction}

Many students perceive a lack of relevance in science and technology (S\&T) education, reported in many countries for decades (Jenkins, 2006; Jidesjö et al., 2009; Wegner et al., 2014). This has profound implications for educational policies, objectives and initiatives. These including 'science for all' aims to ensure that all students have basic knowledge of science and scientific approaches to problems, as well as recognized needs to train future scientists and provide societies with high-quality workforces. Both researchers and policy documents note the severity of the 'relevance problem' (European Commission, 2004, 2007, 2009; Hill et al., 2010; OECD, 2008; Osborne \& Dillon, 2008; Tytler, 2007). They also note the need to initiate developmental work with schools to involve children in meaningful learning

Copyright (C2021 Anders Jidesjö.

DOI: https://doi.org/10.37256/ser.222021772

This is an open-access article distributed under a CC BY license

(Creative Commons Attribution 4.0 International License)

https://creativecommons.org/licenses/by/4.0/ 
environments to fulfill the purposes of S\&T education. However, despite the long acknowledgement of relevance problem and strenuous efforts to counter it, it is still vigorously and recurrently reported.

Education is realized in schools on a daily basis where teachers meet their students in learning activities, and understandings of the teaching and learning of S\&T are produced and subsequently put into practice. Any efforts to change such understandings and associated practices must involve changes to school cultures and mechanisms of educational systems. To initiate meaningful changes to the teaching and perceptions of its relevance, attention must be paid to those who are ultimately responsible for it, i.e. the teachers and their willingness to change practices.

The study presented in this paper uses S\&T education as a concrete case incorporates in a model of teacher professional learning. The development of teacher professional learning is internationally reported. There is no Swedish national research published where this development has been empirically investigated in S\&T education. Such evidence is important to support the development empirically and to investigate possible cultural variation. This was done in the study presented in this paper.

The study accesses a student voice in S\&T education and incorporates it in a model of professional learning for teachers. Hence, the purpose of the study is to investigate students' perception of S\&T education and relate it to teachers' ideas about their practices and school leadership using a professional learning cycle model. The research questions are 1. What is the character of a Swedish S\&T student voice when incorporated in a teacher professional learning cycle? and 2. When confronting teachers and school leadership with the student voice, and what is the character of their response to building the learning cycle further?

In the next section the professional learning model approach is identified by giving a retrospect review of key references in the international reported research development, going from teacher professional development (TPD) to teacher professional learning. Key elements are identified and subsequently adapted to the Swedish context in the research design.

\subsection{The teacher professional learning model approach}

In a review of earlier research on characteristics of effective TPD, Guskey (2003) noted inconsistencies and contradictions in its conceptualization, mainly due to lack of criteria with clear descriptions and contextual factors. The main highlighted factors included teachers content and pedagogical knowledge, and competence in practices that promote students' content learning (see also Borko, 2004). Guskey also concluded that many studies seemed to ignore students' learning outcomes although they are the most important criteria of efficacy, and marginalized students' perspectives in professional development work. A key model by Clarke and Hollingsworth (2002) stresses the importance of focusing on the process through which teachers change or grow professionally. They claimed that the model enabled the identification of 'change sequences' and 'growth networks', recognizing the idiosyncratic and individual nature of teacher professional growth. They pointed out that a key step is to shift from earlier conceptions of change as something that is done to teachers, like an event or sequence of events, to the understanding that change is considered as a complex process involving learning, in both programs and practice. They also advocated recognition that the purpose of TPD is to improve students' learning outcomes. To understand professional development as a process in this manner is one of the elements used in the organizational model used in this paper.

In a review of trends and missing links in TPD in S\&T education, van Driel et al. (2012) used the interconnected model by Clarke and Hollingsworth (2002) and concluded that few studies have considered all domains in the model. Most professional development seems to be conducted outside schools, which excludes observation of and adaptive reflection upon authentic classroom practices. Moreover, few studies have compared different school districts within a country, and very few have included students' perceptions of teacher quality. A problem with this is that schools' organizational aspects, and daily school routines and practices, may not be considered, despite their importance for implementing and sustaining development successfully. In addition, results are often reported, in general, terms and not related to the broader context of an educational innovation. Many studies note the need for expertise, providers and facilitators, but few address the relationships between such actors and outcomes of development programs. Thus, van Driel et al. (2012) urge researchers to consider what matters to teachers in the teaching and learning of subject matter, in relation to students' learning processes and professional development in broader contexts. To let learners report on quality, to include the broad educational context and to make use of facilitators are three additional elements included in the organizational model used in this paper. 
Failure to consider classroom practices and students adequately can also affect teachers' willingness to engage in professional development because it will not provide the learning they need (Opfer et al., 2011). Therefore, involving beliefs, practices and experiential context in professional development is important. Similarly, Ramnarian and Modiba (2013) highlight the importance of fostering self-determination and responsibility rather than dependency. Avalos (2011) adds that there are cultural variations between and within countries, so professional development needs to be tailored to specific situations. The Swedish cultural context is reported in this paper and makes a contribution to this reported shortage in the research literature.

Kriek and Grayson (2009) described a 'holistic professional development' model for South African teachers that included reflection on practice, content knowledge, infrastructure to support collaboration, opportunities to try out new strategies, lifelong learning and teachers' beliefs. Smith (2014) reported a similar two-year professional development programme in Ireland, which included promotion of content and pedagogical knowledge, ongoing and sustained active engagement of participants, and being job-embedded, collaborative and collegial. Smith concluded that it was crucial not only to realize the importance of such factors, but also to combine them. Accordingly, Mansour et al. (2014) advocated the 'revitalization' of professional development which involves connecting teachers with other teachers' and students' needs in a transformative approach rather than retooling and remodeling it. Their work shows the importance of respecting the socio-cultural context of teachers' work to understand professional development as a process and to include what is important for both teachers and their students, e.g. needs for teaching and learning. In the USA, Roehrig et al. (2011) put such programs into practice and found that teachers discovered and realized the power of heeding students' voices. Increasing teachers ability to listen to students ideas influenced knowledge of science teaching activities, leading to enhancement of students' performance (see also Lumpe et al., 2012; Desimone, 2009). Smith (2015) also found that this kind of arrangement improved pupil's attitudes towards science in Ireland.

Despite the need for caution when extending models or extrapolating results to other countries (Avalos, 2011), several studies indicate some potential generalities. Four elements have been identified above. Including a learner perspective in TPD can foster teacher learning and starting from classroom learning practices and relating them to a broader context seems to foster relevance and sustained professional learning, with beneficial effects on students' performance, both cognitive and affective. Such TPD arrangements are often called transformational approaches. In the next sections six more elements are identified to be selected to the organizational model used in this paper.

According to a literature review by Leithwood and Jantzi (2005), important factors for fostering transformational school leadership include prior student achievement, family educational culture, organizational culture, shared school goals and coherent plans and policies. Teachers' age, gender and years' experience in schools were reported to have no effect and school size a mixed effect. In further consideration of leadership aspects of TPD, Timperley (2005) presented key concepts of 'distributed leadership' theory. This type of leadership involves distributing responsibilities among multiple actors and promoting and sustaining conditions that are not dependent on specific individuals rather than focusing on the best way of organizing. Such leadership is not about assigning tasks. It embraces dynamic interactions between multiple leaders with different responsibilities and exploits expertise in an organization by distributing responsibilities in accordance with actors' skills rather than a traditional hierarchy. Timperley argued that this is particularly appropriate in educational contexts since expertise is often situated in people without formally designated roles. Hence, teachers' expertise needs to be coherent with formal leadership roles, and 'boundary-spanners' who can relate to diverse settings, individuals and networks which are particularly crucial. To exploit distributed leadership and use boundary spanners are two additional elements.

Timperley (2011) also argued that research has provided more insights into effective practice per se, than effective leadership that can create such practice. She claimed that there has been too much focused on relationships between adults, while student dimensions have been marginalized. To include a student perspective in teacher learning raises risks of focusing on students' achievements, because it can create a sense of blame and destruction of trust among teaching staff. An alternative approach is to use affective dimensions and to foster a leadership culture with the ability to create a vision that people can relate to as a school mission, underpinned by expectations about student outcomes. Such distributed leadership differs from leadership modes involving greater autonomy and local management roles, which were widely promoted for decades. The element of using affective dimensions when confronting teachers with a student voice is used in the model in this paper.

Muijs et al. (2014) argue that much TPD is not based on research evidence, particularly the demonstrated 
conceptual requirement to regard development as a process rooted in learning, and consistently apply approaches that are coherent with how young people learn. They gathered state-of-the-art evidence regarding teachers' effectiveness, i.e. what teachers do that make important contributions to effective learning for students. Muijs et al. (2014) identified eight factors, each with several elements, and established a model of cyclic knowledge-building to promote positive outcomes for students. The first two steps are to adopt a students' perspective by identifying students' desires and needs, followed by the professional knowledge and skills the teachers need to meet the students' needs. The third step is to deepen professional learning and refine skills, based on the identified needs. This is the point at which many TPD programs start, bypassing the crucial first two steps. Moreover, the actors usually responsible for initiating courses, establishing goals and trying to promote professional learning are not the targeted teachers, who simply engage with the programs or resist them. The first two steps of the cycle are included in the study presented here and empirically investigated. The final steps in the model, before the next cycle begins, are engaging students in new learning experiences and analyzing the impact of changed actions on student outcomes. Muijs et al. (2014) emphasized that this state-of-the-art way of working has consequences for both what it means to be professional and the roles of school leadership in a broad context. A schematic diagram of the model is shown in Figure 1.

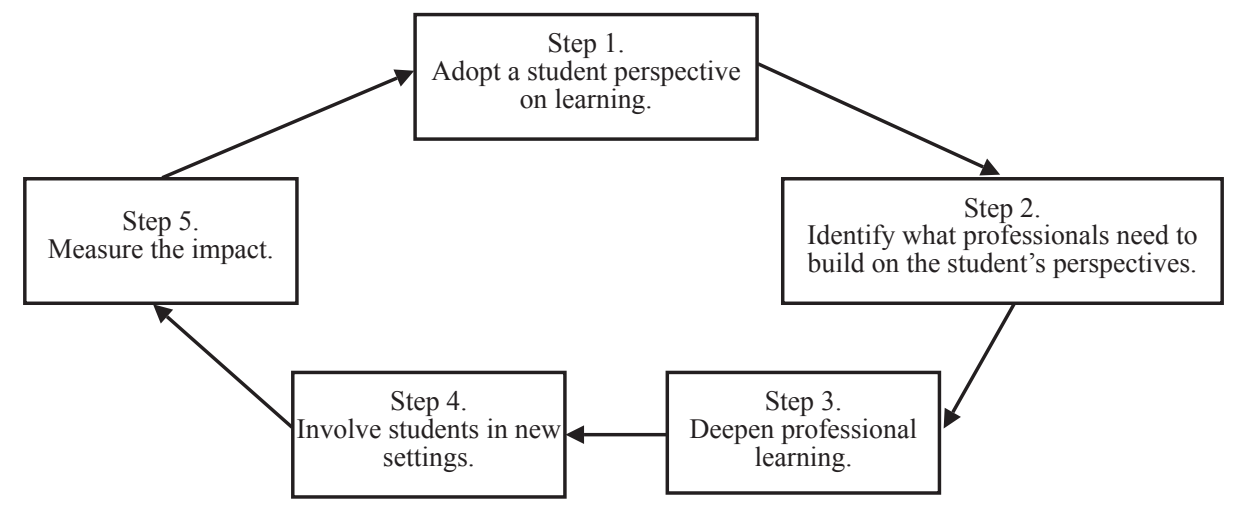

Figure 1. A figure illustrating a knowledge-building cycle for teachers' professional learning starting with students' perspectives on learning S\&T in school. The figure is inspired by the work of Mujis et al. (2014) modified by Jidesjö

In the model presented in Figure 1, Muijs et al. (2014) emphasize that all involved actors should act as professionals, conceptualizing professionalism as adaptive expertise, which includes seeking solutions to identified problems. They claim that the adaptive capacity is fostered when a distributed leadership is attentive and reflective about organization, leadership and students' perspectives, which can enhance the orientation of schools' organization towards learning. To exploit adaptive expertise is an additional element identified.

Several shifts in thinking are reportedly needed (Mujis et al., 2014). TPD should not be regarded as anything delivered to teachers, but as professional learning by multiple actors who use approaches consistent with how people learn. TPD should not be regarded as an activity in which an external expert tells teachers what to do, but as a process in which teachers engage in ongoing collaborative investigation of what works, according to research and experience, and seek support when it is needed. Real students and classroom practices should not be ignored but regarded as reasons to engage and foundations for understanding what needs changing. The process should not be led by single leader or regarded as activities involving single teacher's development. Instead, everyone involved in the of education should be engaged, and understand their functions in relation to shared goals to transform policy into practice (Muijs et al., 2014; Ioannidou-Koutselini \& Frosoula, 2015). To create collaborative inquiry between research and school practice and to stay close to school contexts are two additional elements used in the organizational model in this paper.

This retrospective review identified ten elements important to the shift from TPD to professional learning. These ten elements were adapted to the Swedish cultural context and developed into an organizational model used in the research design. The first two steps in the learning model cycle were included and empirically investigated. 


\section{Materials and methods}

\subsection{Research design}

The design of the study was inspired by theoretical developments in the field of teacher professional learning. Previous studies have identified several important dimensions to consider in efforts to realize school practices in line with these developments. The importance of appropriate organizational elements to foster professional learning in schools has been particularly highlighted. Thus, the first challenge was to identify key elements of an effective approach and operationalize them in an organizational model that would work well in Swedish contexts. In the following they are summed up. The international literature review identified the following 10 elements which were selected in the professional learning model used in this paper:

1. Recognize that professional development is a process.

2. Let learners report on quality.

3. Include the broad educational context.

4. Be aware of relationships of boundary spanners and facilitators.

5. Exploit distributed leadership.

6. Use boundary spanners.

7. Report quality, include affective dimensions.

8. Exploit adaptive expertise.

9. Ensure that researchers and practitioners engage in collaborative inquiry.

10. Create collaborative learning environments, and root developmental efforts in schools' contexts.

In order to combine the 10 elements in a model, there are some important constraints to consider. First, in the Swedish cultural context, national-level actors are responsible for the public administration of education, including the formulation, passage and enforcement of laws, policies, curricula and inspections, as well as provision of some resources for inspiration and development. Municipal-level actors have freedom to interpret the policies within national constraints, and individual teachers can interpret them within national-level, municipal-level and school-level constraints. Municipal-level actors also have responsibility for the professional development or learning of teachers. Thus, the recommendation to include the broad educational context is interpreted here as including relevant activities and practices of municipal-level actors, and their relations to national curricula, regulations, inspection regimes, and provisions for specific development programs.

The exploitation of facilitators element was provided by involvement of the Swedish organization 'Ljungbergsfonden': one of Swedish largest private foundations for funding educational projects in technology, science and entrepreneurship. Schools and municipalities can apply for support from the foundation, thus Ljungbergsfonden can stimulate processes related to $S \& T$ education and act as a facilitator. The processes reported here started in 2015 when Ljungbergsfonden agreed to fund efforts to enhance the perceived relevance of S\&T education in primary to upper secondary schools in five Swedish municipalities.

Substantial efforts were made to create an organization with distributed leadership and adaptive expertise. To foster joint ownership, actors representing different layers of leadership in the municipality's educational organization were invited to workshops, where intelligence analysis and research evidence were presented and discussed in relation to their organizations. Key issues considered included the following questions. Is this a good description? Do we recognize it? Are we already addressing it? If so, what are the foci? What should be developed and why? Do we need more evidence from our own practices? Can we get help by working together with others? Can the learners be involved, and if so how? Such questions were inspired by the research evidence and the continuing processes were developed by facilitating the discussions in the directions framed by the 10 elements applied.

A suggestion that emerged from these activities was to conduct a pre-study in each of the schools involved in the five municipalities. The pre-studies were supposed to include voices of the learners, teachers, principals, head teachers and in some cases politicians to survey the present situation in the organizations. Funds for the pre-studies were applied for and granted by Ljungbergsfonden, thereby clearly establishing the role of a facilitator. The headmaster of each school applying for funding had to commit to efforts to ensure that the school leadership actively participated in the proposed activities. Evidence from the pre-studies is concerned with the organizational steps 1, 2 and 3 in Figure 1, which initiate the knowledge-building cycles. 
To create support for the local pre-studies, a project leader was appointed to act as the boundary spanner for schools in each of the five municipalities. The project leaders gathered research-based evidence and information about locally important relationships and challenges, then reported back to a steering group consisting of the educational head and director of the municipality, and some key persons in the administration. The evidence was reported in stages, to foster awareness of the key local relationships and challenges. This arrangement enabled project leaders to bring together evidence (research and experience based) and connect it with leadership structures with responsibilities for the schools where professional learning was supposed to happen. A lot of time was invested in these steps before any schools were involved.

To support the project leaders, Ljungbergsfonden invited them to regular meetings, in which researchers also participated, during the process. In such meetings the project leaders could learn from each other, be updated on research and policy, get help with the design of the pre-studies and discuss ways to analyze and interpret results. Four such meetings per year were gathered to follow and support the initiated processes. By this, participants were able to link research-based evidence and experience-based knowledge. In the created processes, researchers and practitioners were able to engage in collaborative inquiry and seek solutions to identified challenges, thereby fostering the required adaptive expertise.

Similar exchange meetings were arranged for the participants in the steering groups. Every project leader also had a reference group connected to their work where, for example, researchers, local company representatives and experts gathered to discuss evidence.

During the processes several needs were identified. There were clear indications from the pre-studies that learners wanted more relevance in their S\&T education, and more connections with the surrounding world. From such evidence, actors representing each layers of the educational setting discussed needs to understand societal development and the function of education. When such needs were formulated, the facilitator Ljungbergsfonden could bring in experts to share competence and perspectives with participants (several hundred in some cases) from all the municipalities. Such events raised challenges and stimulated further processes, including group discussions and decisions about what should be followed up locally. Thus, the organizational model enabled schools to exchange experiences, and relate them to local processes and requirements, thereby connecting different levels of the educational setting and displaying for everyone involved ways that leadership was, and could be, distributed.

Establishment of the organization for professional learning could help teachers and their students to feel that they could address issues they considered important. It also promoted respect for, and attention to, experience and the real educational contexts. Moreover, it enabled use of statements by teachers and their students throughout the processes as reminders of the nature of the problem, thus ensuring that the participants remained focused on identified objectives. Through such means, the organizational model and pre-studies served as tools for transformative processes in which research evidence and experience from practice were linked. A schematic diagram of the organizational model with two project leaders is presented in Figure 2.

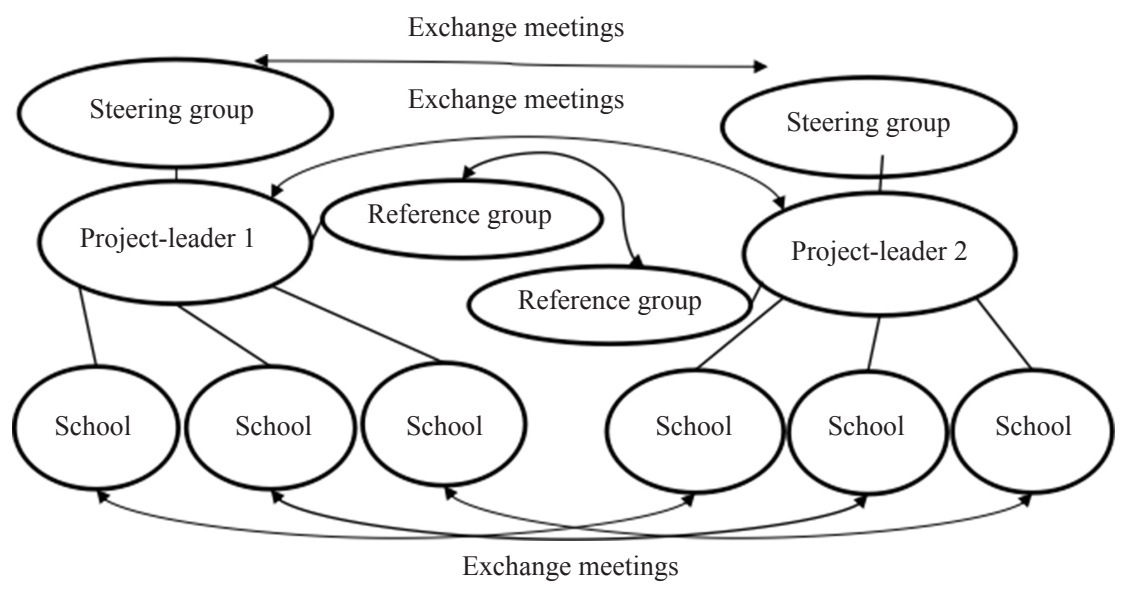

Figure 2. A schematic organizational model to foster professional learning in Swedish school contexts. Additional project leaders with their connected functions and schools can be added 


\subsection{Analysis and sample}

Both questionnaires and semi-structured interviews were used to collect data and cover elements of the organizational model. This paper presents qualitative data obtained from face-to-face group interviews with students, teachers and school leaders in the five Swedish municipalities, which are designated A-E. The interviews varied in time from 30 to 60 minutes and the participants were randomly selected in each participating school. The interviewees' comments were transcribed and subjected to thematic analysis in an iterative manner (Robson \& McCartan, 2016). Initially, responses of the groups in each municipality were analyzed. The findings pertaining to these groups were then compared, and finally the data were combined to identify common themes in the groups' responses. This process resulted in the identification of five themes. Responses that did not provide information related to these themes or purposes of this paper were excluded. Hence, numbers of groups' responses included in the final analysis varied, as shown in Table 1.

Table 1. Numbers of students, teachers, school leaders and schools who contributed. Analyzed responses in each of the five municipalities $(\mathrm{A}, \mathrm{B}, \mathrm{C}, \mathrm{D}$ and $\mathrm{E})$ and in total

\begin{tabular}{|c|c|c|c|c|}
\hline & Primary & Secondary & Upper secondary & Total (n) \\
\hline \multicolumn{5}{|l|}{ Students } \\
\hline $\mathrm{A}$ & 10 & 11 & 34 & 55 \\
\hline $\mathrm{B}$ & 3 & 23 & 14 & 40 \\
\hline $\mathrm{C}$ & 38 & 12 & 7 & 57 \\
\hline D & 0 & 44 & 16 & 60 \\
\hline Sum (n) & & & & 212 \\
\hline \multicolumn{5}{|l|}{ Teachers } \\
\hline A & 2 & 2 & 6 & 10 \\
\hline E & 127 & 22 & 10 & 159 \\
\hline B & 5 & 13 & 6 & 24 \\
\hline $\mathrm{C}$ & 22 & 5 & 5 & 32 \\
\hline $\mathrm{D}$ & 0 & 10 & 0 & 10 \\
\hline Sum (n) & & & & 235 \\
\hline \multicolumn{5}{|c|}{ School leaders } \\
\hline E & 7 & 4 & 1 & 12 \\
\hline B & 4 & 6 & 5 & 15 \\
\hline $\mathrm{D}$ & 0 & 6 & 1 & 7 \\
\hline Sum (n) & & & & 34 \\
\hline \multicolumn{5}{|l|}{ Schools } \\
\hline A & 2 & 2 & 2 & 6 \\
\hline $\mathrm{E}$ & 10 & 3 & 1 & 14 \\
\hline $\mathrm{B}$ & 2 & 4 & 2 & 8 \\
\hline $\mathrm{C}$ & 3 & 1 & 3 & 7 \\
\hline $\mathrm{D}$ & 0 & 6 & 2 & 8 \\
\hline Sum (n) & & & & 43 \\
\hline
\end{tabular}

\section{Results}

The interviews with students, teachers and school leaders provided evidence regarding five themes related to the relevance problem (science is special, the science classroom, progression, organization and ideas for change), as 
sequentially described in the following sections.

\subsection{Science is special}

A common view expressed by students, teachers and school leaders is that science is different from other school subjects, a special domain of knowledge requiring distinct skills.

Social science is more discussion, like general knowledge. You can get it from TV, papers and Facebook. You get it for free if you just follow things. Science is more logic; you have to think and try to understand. You cannot reach a solution by just reasoning. Laws and facts. (Student)

It's fuzzy, nothing concrete. The teacher says, "This is the way it is". Intricate, complicated and lots of studying. You have to divide what the teachers say in pieces to get it into your head. (Student)

It should be made more comprehensible. You need to train [students in] abstract thinking. I need to learn this more to be able to teach it. (Teacher)

Very theoretical subjects, a lot of text, strange terminology, a school language. (School leader)

\subsection{The science classroom}

Several shared understandings of features of science classrooms were identified. Many participants noted needs to listen, take notes, and prepare for both future studies and assessment regimes.

90\% of the time we are being still, listening and taking notes. This makes it very boring, but we learn a lot. (Student)

My students listen to my teaching and take notes. Secondary education is preparatory, and they need to develop these skills, but it should not be excessive. If they are used to hands-on science in primary schools, this is the major change. Our school has a good reputation among upper secondary schools because the science and technology pupils are well prepared, which validates our theoretical approach. (Teacher)

My experiences tell me that science instruction does not chime with today's students. My picture is that students have little influence and there are few connections to daily life. My science teachers are more static in the content they teach, and the process is mostly about preparations for assessments. (School leader)

In some responses, teachers identify problems with students' learning and describe their types of attempts to address the problems. Some of the students also described experiences of such interventions. Typical statements by teachers and students include the following examples:

I often use short clips instead of whole movies which can help. 2D is the closest we can get to reality, and the students appreciate it. (Teacher)

Exciting experiments and laboratory work are where you get the best engagement from the students. This is where you can catch their desire to learn as well as their curiosity. (Teacher)

If clips are good, it can be interesting. Bad animations, slow tempo and a boring voice make it dull. An annoying film from the beginning of the 21st century makes it awkward. (Student)

A film in school often comes straight to the point without a story. You don't listen to it. (Student)

We understand when we do experiments. Investigations are more fun. (Student)

I thought it should be more about explosions, but it wasn't. It made me disappointed. (Student)

Both students and teachers seemed to agree that visualization and inquiry-based science can have helpful qualities, but they may also be demotivational, depending on the structure and setup. Another aspect of this theme, raised by both students and teachers, is the importance of connecting science education with challenges facing society:

I remember a debate we had about genetic modification. I learned a lot from that. (Student)

It would be very interesting to investigate something, but we don't have the time. If we miss some teaching, we 
will get problems in upper secondary education. (Student)

If something happens in society, you could not expect us to work on it; this is never the case. We work with something that the teacher has planned for months, and then you do it. (Student)

This is knowledge that's hard to assess. It's higher-grade content. Even the basic knowledge is not covered [by stories] in the media. (Teacher)

It's hard to be an A-student in grade seven. They have to live with progression. (Teacher)

It can be hard when students start to ask their own questions. Sometimes it can be quite advanced, and they lack the required background knowledge. Populistic and spectacular things can be most difficult to explain.

(Teacher)

The results indicate that students were aware of elements that could make science education more interesting, but they also seemed to be aware that such elements are not very important for future studies. The responses also show that the teachers realized that connections to society and media reports can be relevant and are elements of the grading criteria, but they did not explore the links much due to students' lack of appropriate knowledge and assessment regimes.

\subsection{Progression}

Progression is a common theme of responses of the students, teachers and school leaders. All seemed to be aware that there are problems with progression and changing aspects of various parts of the educational system could potentially enhance learning about science.

Science was more fun earlier. Now we just read and answer questions. (Student)

It's like two completely different subjects. It was fun earlier, now it's the most boring. (Student)

I don't remember anything, because every time we've done something, we immediately start something else, there's no time for repeating. (Student)

It's rushed and complicated. Small things, new things. Too much reading of books. A huge difference between grades six and seven. The teachers don't know our level of understanding. It was much more fun in primary education. (Student)

There should be more text in primary and more practical in secondary. Mix them both! (Student)

We do a lot of things in primary education, but there's often too little theory. We should go through the content to provide the students with knowledge. (Teacher)

We should talk more with each other between the stages, about assessment, aims and how we view them. (Teacher)

Students who get high grades in science often get lower grades in secondary education. Science education starts from scratch and you don't take earlier abilities into consideration. Under this regime, students can lose their self-efficacy. I think this is not how it should be. (School leader)

The responses include corresponding expressions about the perceived difficulty of upper secondary science education:

The science program is demanding and should be for motivated students. It is more appropriate for a few motivated students than for a lot of applicants. (School leader)

Much studying, high pressure. Will I succeed? Our career counselor tells us that we have to study more. You could say she is not encouraging us to study science. (Student)

It's hard, the heaviest. A lot of mathematics. It's extremely demanding. Five hours of studying per day. I don't have a good perception of the science program. (Student)

\subsection{Organization}

When teachers who participated in this study described how education is organized, the aspects they mostly raised were lack of time available for planning, needs for more integration of content and cooperation, and high rates of teacher 
turnover. The school leaders focused more on the teams of teaching staff. The students were described influencing the school environment, rather than education per se.

We try to integrate, but we don't have much time to plan together. It's hard to develop your subject teaching and to work in an integrated way. (Teacher)

I think we could have a better situation if we could plan together, exchange ideas and questions. I also believe a lot in colleagues visiting classrooms. (Teacher)

A lack of qualified teachers and teacher turnover affect both students and teachers. The organization is pulled to pieces. (Teacher)

Sometimes there's a need to work with student matters to maintain order. At other times it's calm, and that's when you can shift focus to work in teams on subject matters. (School leader)

What pupils mostly influence is the school environment; its appearance and what the cafeteria should provide. (School leader)

Students have influence through student council meetings, and we don't have a strategy for other kinds of involvement, which is a concern. (School leader)

Students focused on aspects of organization that they perceived as negative for their learning, such as high turnover of teachers, with a lot of supply teachers, which made them feel insecure and unfairly assessed. Students also complained that they were not informed of teacher exchange and marginalized in planning.

Teachers leave school, but we're never told why. (Student)

We don't have much say. The teachers are in charge of grading criteria and teaching aims, and we can't influence such matters. (Student)

Another aspect of organization raised by the students is that many experienced stresses connected to their schoolwork. They felt that the aim of educational organization was to prepare them for future studies, and the content had little other relevance. They also frequently said that assessment contributed to the stress and dictated what was taught. This was also confirmed by teachers.

The school is so focused on results and achievements, so you forget what you've learned. (Teacher)

\subsection{Ideas for change}

Students, teachers and school leaders also made suggestions for improvement. Students raised the importance of more time for planning and listening to the students. They noted that teachers could talk to them and ask them, like the interviewer did in this study. They disliked small working areas, and wanted more study visits, fieldwork, projects and film, less teacher-led instruction and more explanation why they needed to learn the presented content. They expressed desires for more dialog about the kind of help they needed, and more attention to recent discoveries and connections with occupations and society. They felt that drama, quizzes, questionnaires, group work and ability to move around could be helpfully incorporated into science lessons. Other mentioned desires were clearer lesson plans, aims, demands and expectations, more discussion and more peace and quietness. Ideas that teachers and school leaders raised are exemplified by the following excerpts.

You need to be passionate when teaching. It has an effect on the students and they cannot miss it. Connecting to reality is the be-all and end-all. If you don't have it, you have to learn it. (Teacher)

Updating teaching aids and providing us with more advanced laboratory equipment would make science more interesting for the students. The organization should be changed to create scope for cooperation between teachers. (Teacher)

I believe in change from inside because it will last. I don't believe in plenary lecture sessions and new fancy teaching aids. (Teacher)

The guiding question should be, what happens in the classroom? (Teacher) 
There's a leadership problem. We feel that we have their support, but we're left alone to do the work. (Teacher) We should have a network, or share ideas, visit classrooms. I participate in Facebook groups and it's up to me. We could share and discuss things more. (Teacher)

It's important to be creative and teachers need support in being that. Digital resources are tools. Students need to see, to get a picture. (School leader)

I'd like a lively pedagogic discussion. We need to talk about how to meet students where they are, to catch them and give them actual influence. (School leader)

I believe I have skilled teachers, but they're stuck in a system. (School leader)

Content is more about organizing than abilities. (School leader)

We need active participation from the students, a participatory culture. (School leader)

Overall, the responses show awareness of school science culture and traditions, as well as possible improvements, such as more collaboration between teachers and initiating change from within the system rather than through lectures by an external expert.

\section{Discussion}

In the cyclic knowledge building model Muijs et al. (2014) developed to promote important outcomes for students, the first two steps deal with the knowledge and skills students and teachers respectively need to create processes of professional learning. These steps have generally been neglected in earlier work but included in the present study and empirically investigated.

Results of the pre-studies concern them. Muijs et al. (2014) argue that they are crucial for creating responsibilities and awareness of situations in local classrooms. This is important for starting processes from within, as confirmed by the ideas for change raised by the participants. For this, several needs and skills were identified, but they were not always consistent or compatible. The participants' responses are not easy to interpret. The results section reports common themes in the responses, to focus on shared issues that could be targeted in joint work. However, it does not mean that the five identified themes are necessarily the most important to address in further initiatives. It rather demonstrates the importance of identifying, addressing and reporting key aspects of specific school cultures (van Driel et al., 2012). Starting from within is embedded in the teacher professional learning model, which also implies that initiated processes should be regarded as dynamic.

There is no claim in the study reported here to argue that the results are generalizable. Rather the opposite, to show concrete ways that internationally reported research can be adapted to a national context which is a reported research shortage (Avalos, 2011). The generalizability of the results may not be the most important issue, but it is an aspect to consider in continued reporting. Many of the participants' statements confirm the relevance problem of S\&T education in school, which makes many students reluctant to pursue science studies (Jenkins, 2006; Jidesjö et al., 2009). This is an overall answer to the research questions in this paper and it is a problem which has been widely reported (European Commission, 2009; Hill et al., 2010; OECD, 2008; Osborne \& Dillon, 2008; Tytler, 2007). In spite of this, the voice of the learners is largely neglected in the literature about teacher professional learning. Literature concerned with students' interest in science and teacher professional learning seems to converge and could be used together in further work.

The importance of accessing this view is illustrated by the students that "science is special". van Driel et al. (2012) argue that subject matter probably has little importance for processes of professional learning, but our results indicate quite the opposite. There is a clear message that S\&T in school is special and embedded in specific traditions which are an empirical answer to the first research question in this paper. The result has clear implications for aspects that require improvement and for that reason, should be included in the next step of the knowledge building model. The content dimension should be carefully considered in continuous work, and its importance could probably be more explicitly and clearly included in the professional learning model.

In the conceptualization of professionalism as adaptive expertise, Muijs et al. (2014) recommend avoidance of focusing on students' achievements because it can generate blame game and feelings of guilt among teacher staff. Affective approaches are potentially helpful alternatives. A critical question is whether the issues they raise are easier to tackle for a teacher team which is what the second research question is concerned with. The empirically identified issues 
from the students are strongly connected to S\&T teaching traditions in different stages of the educational system. Lack of relevance seems to permeate the whole system and increase with progression. Our evidence indicates that teachers are aware of the situation and have arguments for not attempting to enhance relevance. Some of their responses indicate that teachers believe modern S\&T to be too difficult or sophisticated to include in the basic knowledge students should learn in school. They believe it to be hard to teach, because the knowledge underlying some of the issues reported in the media is 'hardcore science'. They also believe it to be difficult, higher-grade content that is difficult to assess, and that students do not have the knowledge required to discuss such matters. These are all empirically identified findings giving concrete character to a teacher response to a student voice which creates the prerequisites for further steps in the professional learning cycle.

The students' responses indicate that they do not believe they can influence planning, and accordingly the teachers did not mention their importance in planning. One interpretation of the findings is that both students and teachers are aware of what could be done to enhance learning, but certain traditions and established practices hinder their adoption. Hence, a challenge lies in applying identified knowledge and skills to deepen teachers' professional knowledge and skills, thereby engaging students in new learning experiences. This is where the distributed leadership with adaptive expertise to establish common processes oriented towards common goals becomes important and requires further investigation.

Furthermore, the evidence from students indicates a tradition of practical activities in primary S\&T education, with limited explanation of observed phenomena through texts, notes, and lectures. Despite the lack of theoretical underpinning, students seem to enjoy primary S\&T education, but the enjoyment declined at secondary level due to excessively passive learning through lecturing by teachers, note-taking and rapid introduction to concepts without connection to relevant contexts.

Teachers' understanding of the importance of preparing students for future studies and assessment regimes seems to be a major reason for this. Paradoxically, however, few students are prepared for future science studies as most choose other educational programs. Thus, the adults' perceptions of students' situations are not coherent with the students' own perceptions and actions. This disjunction seems starkest in the transition between secondary and upper secondary S\&T education when school leaders and study councilors recommend students to abandon further S\&T studies if they are not willing to sacrifice their lives for studies.

This corroborates the importance of including voices of learners, teachers and school leaders in pre-studies to reveal, to all involved actors, the true nature of practices, activities and behavior in their respective organizations. Although similar findings have been reported and could be disseminated to people in leadership positions through lectures and seminars (which was also done in the processes reported here), it is important to discover local conditions before seeking solutions. Research articles may have little local relevance due to setting and cultural bias. However, consistent messages from within an organization should not be ignored and trigger recognition of a need for change, vitalizing the educational setting rather than retooling it (Mansour et al., 2014). The evidence also indicates that different problems are associated with different parts of the educational system, calling for different measures to address them. Thus, the teacher professional learning model should be sufficiently flexible to accommodate diverse school cultures, as well as findings obtained from further studies.

Combining the outcome of the results presented here gives an identification of effective strategies to enhance the relevance of S\&T education. The findings highlight two main strategies: establishment of an organization that promotes distributed leadership with adaptive capacity and use of pre-studies as a transformative tool. The two approaches are interconnected and thus discussed together here.

The research design, involving municipality-level organization and Ljungbergsfonden as a facilitator, was refined during the work. The theory of distributed leadership presented by Timperley (2011) was applied in the Swedish school context and has important implications. In order to establish effective professional learning, it implies needs to establish shared goals throughout an educational organization and provide school leaders with the support of the whole organization, rather than leaving single leaders unsupported in local management roles. In the Swedish context this means involving municipality-level actors because they have formal responsibility for education. It also highlights the need to apply results of international studies judiciously and adapt core concepts in an appropriate organizational model in efforts to ensure that decisions have the support of all people involved in a focal organization.

Timperley (2005) argued that in educational practices expertise is mostly situated in people without formal 
leadership roles. Hence, teacher expertise is not coherent with leadership structures and to address this problem she recognizes a need for 'boundary spanners', capable of tackling both 'critical externalities' and 'schooling internalities' (see also Forde \& Dickson, 2017). In the conceptualization of the organizational model presented here, this role was assigned to project leaders, since they moved and mediated transfer of information between school practitioners and steering groups. Each steering group had the capacity to take decisions and support further efforts. Its members were also regularly informed about situations in the organization they were responsible for which fosters responsibility, rather than dependency (Ramnarian \& Mobida, 2013) relations between actors. This is a concrete example of how the concept of boundary spanners can be adapted and treated in a Swedish cultural context.

According to van Driel et al. (2012), previous researchers have claimed that facilitators are needed, but not described empirically based functions for them. In the initiative presented here, Ljungbergsfonden acted as a facilitator and provided funds for pre-studies and arranged meetings for the project leaders and other participants, thereby promoting development and implementation of adaptive expertise. The municipalities could probably have done this themselves, without facilitators, but in Sweden they could not. There may be several reasons for this, some of which may be cultural and warrant further attention. The findings indicate that a facilitator can play an important role, which is not solely financial: Ljungbergsfonden's funding was tiny compared to the school budgets of the municipalities involved. More important was the shift in the approach it facilitated, away from the previous concept focused on the professional development of individual teachers, to promoting a process in which everybody in the organization addressed common problems. This is the key characteristic of facilitation, and the study illustrates concrete ways of fostering the required relationships in a Swedish cultural context. The reliability of this way of putting it needs further investigation. Timperley (2011) argued that different actors need to step in at different stages of a mission to maintain realization of a vision, and that both declarative and procedural knowledge are essential to facilitate changes in practices that increase teaching's effectiveness for students. Hence, facilitators require specific competences, and previous research has underestimated the deep knowledge required about the teaching and learning of S\&T to facilitate their improvement. In the study reported here, this role was fulfilled by boundary spanners who could act on various stages and connect people with appropriate expertise when necessary.

A major consideration during the design of the professional learning initiative was to ensure that the processes were rooted in identified needs and demands of learners and teachers in the organization (the first two steps in the professional learning cycle). This involved ensuring that descriptions of teachers' needs were influenced by voices of the learners, thereby avoiding the frequent problem of focusing too much on relationships among adults (Timperley, 2011). As confirmed by van Driel et al. (2012), students seem to have been almost forgotten in some previous TPD work. Much TPD seems to have been conducted outside schools, leaving classroom realities and organizational contexts behind. In the work presented here, students' views were collected in pre-studies which highlighted several common features from classroom realities. Interestingly, the teachers' and school leaders' perspectives provided complimentary indications and possible improvements. The reported results confirm that voices of students, teachers and school leaders are equally important for effective teacher professional learning. The pre-studies developed here as a tool, is a concrete way of doing it. The evidence from multiple groups of actors also enhanced the trustworthiness of the results, and validation of the processes, which is important to investigate in further studies.

The findings indicate that educational traditions should be carefully considered in assessments of students' requirements for learning. Avalos (2011) warned of cultural biases when comparing TPD studies, but there is also evidence that traditions can be parts of larger cultural movements (Lyons, 2006). This does not mean that the situation is the same in every country, nor that all students have the same perception. If carefully applied, such evidence can be used to relate locally collected evidence with research findings in the knowledge-building cycle presented by Muijs et al. (2014). The present study contributes by describing a way to do this, by operationalizing the first two steps in the cycle in a Swedish context.

In conclusion, the international research concerned with the theoretical development of teacher professional learning could be used to identify key elements and include them in an organizational model. The organizational model can be used to create a professional learning cycle in schools, with judicious adjustment in accordance with local conditions and contexts. Application of the model highlighted the importance of addressing the relevance problem. S\&T was found to be regarded as 'special' by learners, teachers and school leaders, and to have differing characteristics at different stages of the educational system. Teachers' reactions to a student voice were found to be divergent. On the one 
hand, they seem to be aware of the problem, but they also have arguments for not considering it in the teaching of S\&T. This has clear practical implications for the knowledge building cycle of professional learning which is important to investigate further.

A last comment is that learners, teachers and school leaders observe and describe aspects of their school routines that are important to them, if they are invited to do so. They also make suggestions for improvement. The professional learning approach works. This confirms that at least some parts of solutions to the relevance problem of S\&T education can be constructed from inside educational systems, if supported by the organization. This approach to the problem is to make use of theoretical developments of teacher professional learning. A new robust approach.

\section{Acknowledgements}

The work was funded by Ljungbergsfonden in Sweden. Managing director Sara Jons, thank you very much. Thanks a lot, to all project leaders, students and their schools, with teachers and school leaders who took part and made the necessary arrangements. All others involved-Many thanks!

\section{References}

Avalos, B. (2011). Teacher professional development in teaching and teacher education over ten years. Teaching and Teacher Education, 27(1), 10-20.

Borko, H. (2004). Professional development and teacher learning: Mapping the terrain. Educational Researcher, 33(8), 3-15.

Clarke, D., \& Hollingsworth, H. (2002). Elaborating a model of teacher professional growth. Teaching and Teacher Education, 18(8), 947-967.

Desimone, L. M. (2009). Improving impact studies of teachers' professional development: Toward better conceptualizations and measures. Educational Researcher, 38(3), 181-199.

European Commission. (2004). Europe needs more scientists. Report by the High Level Group on Increasing Human Resources for Science and Technology in Europe 2004. Luxembourg, Belgium. https://doi.org/92-894-8458-6

European Commission. (2007). Science Education Now: A renewed pedagogy for the future of Europe. Belgium. https:// doi.org/1018-5593

European Commission. (2009). She Figures 2009. Statistics and Indicators on Gender Equality in Science. Germany. https://doi.org/978-92-79-11388-8

Forde, C., \& Dickson, B. (2017). The place of leadership development for change agency in teacher education curricula for diversity. In L. Florian \& N. Pantić (Eds.), Teacher Education for the Changing Demographics of Schooling (pp. 83-99). Springer, Cham. https://doi.org/10.1007/978-3-319-54389-5_7

Ioannidou-Koutselini, M., \& Frosoula P. (2015). Engaging school teachers and school principals in an action research in-service development as a means of pedagogical self-awareness. Educational Action Research, 23(2), 124-139.

Jenkins, E. W. (2006). The student voice and school science education. Studies in Science Education, 42(1), 49-88.

Hill, C., Corbett, C., \& St. Rose, A. (2010). Why So Few? Women in Science, Technology, Engineering and Mathematics. Report Published by the American Association of University Women (AAUW). Washington, USA. https://doi. org/978-1-879922-40-2

Jidesjö, A., Oscarsson, M., Karlsson, K-G., \& Strömdahl, H. (2009). Science for all or science for some: What Swedish students want to learn about in secondary science and technology and their opinions on science lessons. NorDINA, $5(2), 213-229$.

Leithwood, K., \& Jantzi, D. (2005). A review of transformational school leadership research 1996-2005. Leadership and Policy in Schools, 4(3), 177-199.

Lumpe, A., Czerniak, C., Haney, J., \& Beltyukova, S. (2012). Beliefs about teaching science: The relationship between elementary teachers' participation in professional development and student achievement. International Journal of Science Educaion, 34(2), 153-166.

Lyons, T. (2006). Different countries, same science classes: Students' experiences of school science in their own words. International Journal of Science Education, 28(6), 591-613.

Muijs, D., Kyriakides, L., van der Werf, G., Creemers, B., Timperley, H., \& Earl, L. (2014). State of the art-teacher ef- 
fectiveness and professional learning. School Effectiveness and School Improvement, 25(2), 231-256.

Opfer, V. D., Pedder, D. G., \& Lavicza, Z. (2011). The role of teachers' orientation to learning in professional development and change: A national study of teachers in England. Teaching and Teacher Education, 27(2), 443-453.

Osborne, J., \& Dillon, J. (2008). Science Education in Europe: Critical Reflections. A report to the Nuffield Foundation, London.

Ramnarian, U. D., \& Mobida, M. (2013). Critical friendship, collaboration and trust as a basis for self-determined professional development: A case of science teaching. International Journal of Science Education, 35(1) 65-85.

Robson, C., \& McCartan, K. (2016). Real World Research: A resource for users of social research methods in applied settings (4th ed.). Wiley: John Wiley Sons Inc.

Roehrig, G. H., Dubosarsky, M., Mason, A., Carlson, S., \& Murphy, B. (2011). We look more, listen more, notice more: Impact of sustained professional development on head start teachers' inquiry-based and culturally-relevant science teaching practices. Journal of Science Education and Technology, 20(5), 566-578.

Smith, G. (2014). An innovative model of professional development to enhance the teaching and learning of primary science in Irish schools. Professional Development in Education, 40(3), 467-487.

Smith, G. (2015). The impact of a professional development programme on primary teachers' classroom practice and pupils' attitudes to science. Research in Science Education, 45(2), 215-239.

Timperley, H. (2005). Distributed leadership: Developing theory from practice. Journal of Curriculum Studies, 37(4), $395-420$.

Timperley, H. (2011). Knowledge and the leadership of learning. Leadership and Policy in Schools, 10(2), $145-170$.

Tytler, R. (2007). Re-imagining Science Education. Engaging students in science for Australia's future. The Australian Council for Educational Research (ACER) Press. https://doi.org/978-086431-725-4

van Driel, J. H., Meirink J. A., van Veen, K., \& Zwart, R. C. (2012). Current trends and missing links in studies on teacher professional development in science education: A review of design features and quality of research. Studies in Science Education, 48(2), 129-160.

Wegner, C., Strehlke, F., \& Weber, P. (2014). Investigating the differences between girls and boys regarding the factors of frustration, boredom and insecurity they experience during science lessons. Themes in Science \& Technology Education, 7(1), 35-45. 